\title{
Effect of thermal and hygrothermal aging on the plane stress fracture toughness of poly(ethylene terephthalate) sheets
}

\author{
T. Bárány ${ }^{*}$, E. Földes ${ }^{2}$, T. Czigány ${ }^{1}$ \\ ${ }^{1}$ Department of Polymer Engineering, Faculty of Mechanical Engineering, Budapest University of Technology and \\ Economics, H-1111 Budapest, Múegyetem rkp. 3., Hungary \\ 2Department of Polymer Physics and Chemistry, Institute of Chemistry, Chemical Research Center, Hungarian Academy \\ of Sciences, H-1525 Budapest, P.O. Box 17, Hungary
}

Received 24 January 2007; accepted in revised form 7 March 2007

\begin{abstract}
The in-plane (plane stress) fracture toughness of two polyester (PET, PETG) sheets were assessed using the essential work of fracture (EWF) method after thermal and hygrothermal aging performed just below glass temperature. This ensured that physical aging takes place. On the aged sheets the yield stress $\left(\sigma_{y}\right)$, enthalpy relaxation $(\Delta H)$ and EWF parameters were determined. It was observed that the essential work of fracture component related to the specific yielding $\left(w_{e, y}\right)$ is suitable for assessing physical aging - independently of the humidity content. A good linear correlations exists between $w_{e, y}, \sigma_{y}$ and $\Delta H$.
\end{abstract}

Keywords: fracture and fatigue, essential work of fracture (EWF), fracture toughness, physical aging, hygrothermal aging

\section{Introduction}

The transparency of polyesters (e.g. PET bottles) is ensured by a rapid cooling applied during processing, when the material gets into a metastable, amorphous state, characterized by the absence of long-term order. When polymers are below their glass temperatures $\left(T_{g}\right)$, the positions of molecular chains are fixed but the free volume is still significant. The free volume - as well as the temperature - has a significant impact on the mobility of the molecular chain segments. The polymeric systems being in metastable state approach an equilibrium state through slow molecular relaxation. Owning to this process the free volume and mobility of the segments decrease, which results in embrittlement. This slow process is called physical aging and depends on the temperature. The relaxation time decreases exponentially with increasing temperature. In case of PET - used under $T_{g}$ - the relaxation is very slow, so noticeable change in the properties can occur after only after several years. This explains the use of accelerated aging at higher temperature.

The polyesters are applied both in the absence (dry) and in the presence of water (in wet state, in contact with soft drinks or mineral water). Under wet condition PET absorbs water, the amount of which approaches to the saturation value determined by the ambient parameters. Moisture content increases the molecular mobility significantly, i.e. it reduces the relaxation time, since water acts as a plasticizer. Physical aging has varying importance in case of dry air [1,2], in presence of humidity [3] and in plasticized systems [1] and it can have very differ-

*Corresponding author, e-mail: barany@pt.bme.hu

(C) BME-PT and GTE 
ent effects on the mechanical and fracture properties of polymers. In case of polyester foils stored under normal conditions significant deterioration can occur in even a couple of years. It is important to know, however, how the properties of material change under higher humidity conditions during storage and use.

The embrittlement induced by physical aging can be assessed by determining of the change in the yield stress $\left(\sigma_{y}-\right.$ tensile tests) [2-4]. Furthermore it can be characterized by measuring the enthalpy relaxation $(\Delta H$ - differential scanning calorimetry, DSC) [2, 5-7]. Physical aging also influences the fracture mechanical properties of the polymer but only relatively few studies have been published so far. $[1-4,7]$. For assessing the fracture characteristics of ductile, tough polymers the Essential Work of Fracture (EWF) method has gained acceptance recently $[1-4,7-15]$, which has been developed mainly for in-plane load on single- and doubleetched notched tensile specimens (SEN-T $[12,13]$ and DEN-T [1, 14, 15], respectively) and used widely. The advantage of DEN-T specimen is its symmetry, i.e. the distortion of the sample due to loading can be avoided, especially when the specimen is too long and narrow.

The goal of the present study is to prove the applicability of the plane-stress essential work of fracture method for monitoring the effect of physical and hygrothermal aging.

\section{EWF method}

The EWF theory (see Refs. $[1,2,4,7]$ and references therein), credited to Broberg, splits the total energy required to the fracture of a pre-cracked specimen into two components: the essential $\left(W_{e}\right)$ and non-essential work $\left(W_{p}\right)$ of fracture. $W_{e}$ is needed to fracture the polymer in the crack propagation zone and thus to generate new surfaces. $W_{p}$ is the actual work consumed in the outer plastic region, where various energy dissipation mechanisms take place. The total fracture energy, $W_{f}$, calculated from the area of the force-elongation curves, can thus be expressed by Equation (1):

$W_{f}=W_{e}+W_{p}$

Considering the surface- (i.e. $L t$ ) and volumedependence (i.e. $L^{2} t$ ) of the constituent terms, Equation (1) can be rewritten using these specific terms (2), (3):

$W_{f}=w_{e} L t+\beta w_{p} L^{2} t$

$w_{f}=\frac{W_{f}}{L t}=w_{e}+\beta w_{p} L$

where $L$ is the ligament length, $t$ is the specimen thickness and $\beta$ is a shape factor related to the shape of the plastic zone. The basic prerequisite of the EWF method is that the ligament $(L)$ of the specimen should fully yield before the crack propagation starts. Based on Equation (3), we can be determined from the intercept of the linear regression curve fitted to the plot of $w_{f} v s . L$.

It was found that $w_{e}$ is a composite term under plane-stress conditions consisting of a yielding $\left(w_{e, y}\right)$ and a necking+tearing $\left(w_{e, n}\right)$ component. The force-elongation behavior displayed in Figure 1a allowed us to separate the specific work of fracture required for yielding $\left(w_{y}\right)$ and that consumed by necking+tearing $\left(w_{n}\right)$. As a consequence, the data
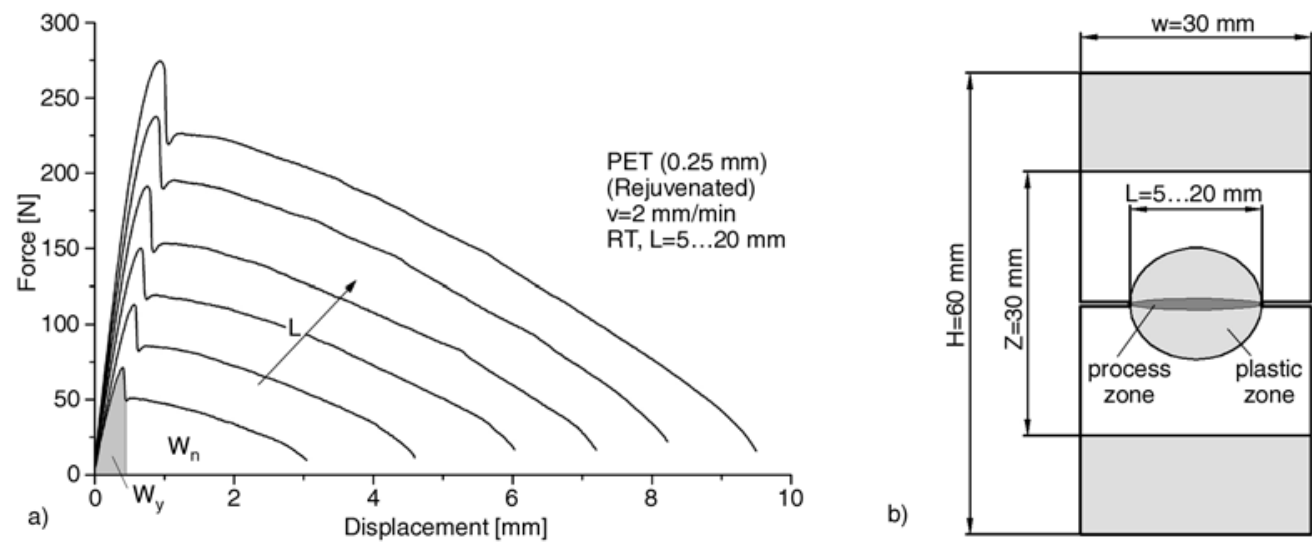

Figure 1. a) Characteristic force-elongation curves of PET (RJ) showing the energy partitioning, b) Dimension of the DDEN-T specimens 
reduction given by Equation (3) changed to (4), (5), (6) $([1-4,8,11,14,15]$ and references therein):

$w_{f}=w_{f, y}+w_{f, n}=w_{e}+\beta w_{p} L$

$w_{f, y}=w_{e, y}+\beta^{\prime} w_{p, y} L$

$w_{f, n}=w_{e, n}+\beta^{\prime \prime} w_{p, n} L$

This energy partition has been proved experimentally for several ductile polymer sheets $([1-4,8,11$, $14,15]$ and references therein).

Under plane stress condition the EWF approach can be applied, if the following requirements are fulfilled:

1. The total yielding of the ligament and necking should precede crack propagation.

2. Geometrical similarity of the $F-x$ curves registered on DEN-T specimens with different ligament lengths.

3. $L \leq 2 R_{p}$, which ensures the complete yielding of ligament prior to crack propagation. In this case a linear correlation between $W_{p}$ and $L^{2}$ exists. $R_{p}$ is the radius in the plastic zone at the crack tip.

4. $L \leq W / 3$ which ensures that the edge effects are avoided, i.e. plastic deformation occurs within the ligament region.

5. $L \geq(3-5) t$, which ensures pure plane stress in the ligament region avoiding the plane stress/ plane strain transition.

Based on the above written criteria, the ligament lengths are limited by the following relation (7):

$(3-5) t \leq L \leq \min \left(2 R_{p} ; \frac{W}{3}\right)$

Note that the upper limit of the applicability of this method was determined for metals therefore it can be stated according to the related literature that this restriction is too conservative for ductile polymers [14-16].

\section{Experimental}

\subsection{Materials and their aging}

Two kinds of amorphous copolyester sheets (PET 9921, PETG 6763) produced by a twin-screw extruder $\left(T=220-240^{\circ} \mathrm{C}, 90 \mathrm{rpm}\right)$ followed by chill roll sheeting $\left(T=65^{\circ} \mathrm{C}\right)$, were provided by Eastman Chemical Company (Kingsport, TN).
Sheets with a thickness of approximately $0.3 \mathrm{~mm}$ were studied both after rejuvenation (RJ) and aging for 6-264 hours. The rejuvenation and the aging were performed in a thermostatic oven 87 and $67^{\circ} \mathrm{C}$, respectively. Note that the former temperature is just above the glass transition temperature $\left(T_{g}=74\right.$ and $\left.77^{\circ} \mathrm{C}\right)$, whereas the latter one is below $T_{g}$. In order to keep the sheet form, the sheets were sandwiched between two preheated glass plates (ca. $4 \mathrm{~mm}$ thick each). During hygrothermal aging the sheets were immersed in distilled water.

\subsection{Material characterization}

For the determination of enthalpy relaxation differential scanning calorimetry (DSC) traces were recorded on a Mettler DSC 821 device in the temperature range from -50 to $+300^{\circ} \mathrm{C}$ at a heating rate of $20^{\circ} \mathrm{C} / \mathrm{min}$. In case of hygrothermal aging the DSC tests were run on the sample after it was dried under ambient conditions. For the determination of enthalpy relaxation spline approach was selected.

\subsection{Specimens and their testing}

The specimens were oriented along the machine (film production) direction. Static tensile mechanical properties were determined on dumbbells (1B, according to EN ISO 527) at room temperature $(R T)$ and at a crosshead speed of $v=2 \mathrm{~mm} / \mathrm{min}$. For the EWF study, double edge-notched specimens (DEN-T) were subjected to tensile loading at room temperature at the aforementioned deformation rate. The dimensions of the DEN-T specimen are given in Figure $1 \mathrm{~b}$. The free ligament length of DEN-T specimens ranged from $L=5$ to $20 \mathrm{~mm}$. For every ligament length five specimens were prepared and tested.

\section{Results}

\subsection{Tensile tests}

Earlier it was demonstrated that yield stress can be a suitable parameter for determining the effects of the plasticizer on the physical aging that occurred in normal environment [1]. Figure 2 shows the change of the yield stress after thermal and hygrothermal aging. The related values are listed in Table 1. One can see that the thermal aging caused embrittlement and increased $\sigma_{y}$ for both materials. In contrast, hygrothermal aging decreased the yield 
Table 1. Yield stress $\left(\sigma_{y}\right)$ and enthalpy relaxation $(\Delta H)$ results for PET and PETG sheets thermally/hygrothermally aged for $0 . .264$ hours

\begin{tabular}{|c|c|c|c|c|c|c|c|c|}
\hline \multirow{3}{*}{$\begin{array}{c}\text { Aging time } \\
{[\mathrm{h}]}\end{array}$} & \multicolumn{4}{|c|}{ Thermal aging } & \multicolumn{4}{|c|}{ Hygrothermal aging } \\
\hline & \multicolumn{2}{|c|}{ PET } & \multicolumn{2}{|c|}{ PETG } & \multicolumn{2}{|c|}{ PET } & \multicolumn{2}{|c|}{ PETG } \\
\hline & $\begin{array}{c}\sigma_{\mathrm{y}} \\
{[\mathrm{MPa}]}\end{array}$ & $\begin{array}{c}\Delta \mathbf{H} \\
{[\mathrm{kJ} / \mathbf{k g}]}\end{array}$ & $\begin{array}{c}\sigma_{\mathrm{y}} \\
{[\mathrm{MPa}]}\end{array}$ & $\begin{array}{c}\Delta \mathbf{H} \\
{[\mathrm{kJ} / \mathrm{kg}]}\end{array}$ & $\begin{array}{c}\sigma_{\mathrm{y}} \\
{[\mathrm{MPa}]}\end{array}$ & $\begin{array}{c}\Delta \mathbf{H} \\
{[\mathrm{kJ} / \mathbf{k g}]}\end{array}$ & $\begin{array}{c}\sigma_{\mathrm{y}} \\
{[\mathrm{MPa}]}\end{array}$ & $\begin{array}{c}\Delta \mathbf{H} \\
{[\mathrm{kJ} / \mathrm{kg}]}\end{array}$ \\
\hline $0(\mathrm{RJ})$ & 52.3 & 0.98 & 46.6 & 1.04 & 52.3 & 0.98 & 46.6 & 1.04 \\
\hline 6 & 58.0 & 3.46 & 51.8 & 2.72 & 40.6 & 1.08 & 40.1 & 1.12 \\
\hline 24 & 58.8 & 4.71 & 52.8 & 3.23 & 39.9 & 1.13 & 41.6 & 1.24 \\
\hline 96 & 58.9 & 4.92 & 54.3 & 3.59 & 39.7 & 1.31 & 41.9 & 1.41 \\
\hline 264 & 59.8 & 5.53 & 55.2 & 4.37 & 42.3 & 1.49 & 46.0 & 1.78 \\
\hline
\end{tabular}

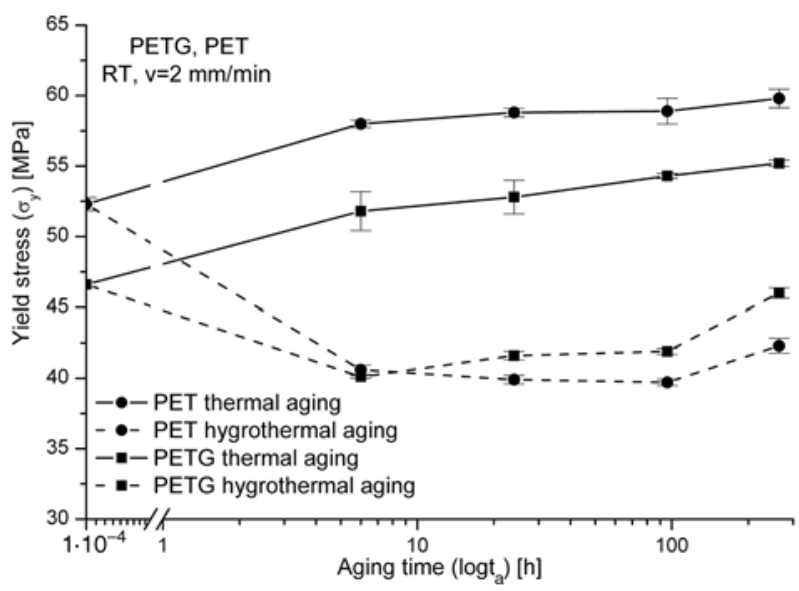

Figure 2. The change of yield stress $\left(\sigma_{y}\right)$ as a function of aging time $\left(\log t_{a}\right)$

stress after the first 6 hours (the humidity content after ca. 6 hours reaches its saturation value - ca. $1 \mathrm{wt} \%)$. After hygrothermal aging physical aging manifested for PETG (yield stress increased). For PET a minor decrease can be experienced up to 96 hours and after physical aging occurred.

\subsection{Morphological tests}

Physical aging can be assessed by measuring the enthalpy relaxation $(\Delta H)$ with DSC. Figures $3 \mathrm{a}$ and $3 \mathrm{~b}$ present the DSC curves of thermally aged PET and hygrothermally aged PETG, respectively. The enthalpy relaxation can be determined by integrating the area designated by grey color (Figure 3 ). Figure 4 shows $\Delta H v s$. aging time in semi-logarithmic scale and Table 1 contains its values. Note that thermal aging influences $\Delta H$ similarly to the yield stress, but hygrothermal aging affects it to a much smaller extent after soaking in water at $67^{\circ} \mathrm{C}$. The reason is that the water molecules diffused inbetween the molecular chains, therefore the molecular mobility increases, the relaxation time decreases, so does $\Delta H$.
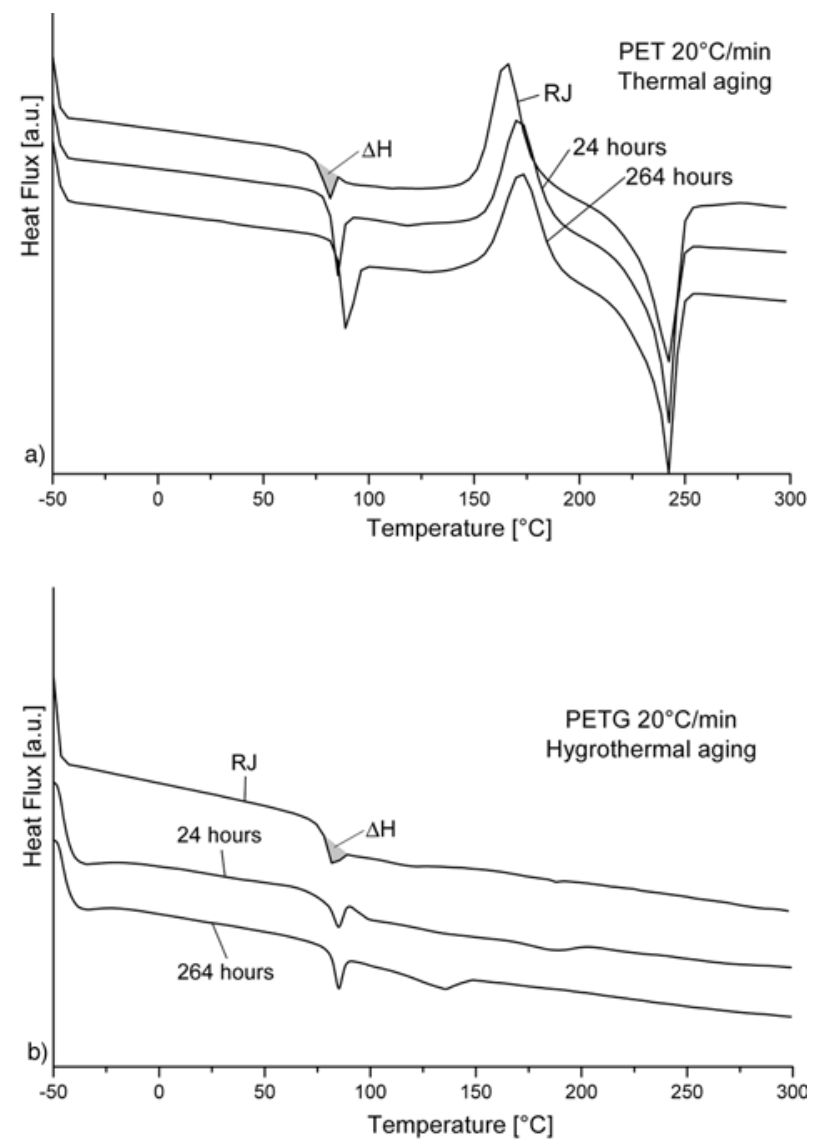

Figure 3. a) DSC curves of thermal aged PET, b) DSC curves of hygrothermal aged PETG

As it is presented above, $\sigma_{y}$ changes significantly due to this complex effect, both elements (physical aging and the plasticizing effect of water) influence its value considerably. The enthalpy relaxation cannot or can slightly evolve owning to the higher molecular mobility caused by the presence of water molecules. The amount of absorbed water increases continuously up to 6 hours and reaches its saturation value, i.e. humidity content of the investigated polyesters from this time on is constant. So, the change of the enthalpy relaxation refers to the physical aging of this plasticized material. Therefore it is not worth to look for correlation with the initial 


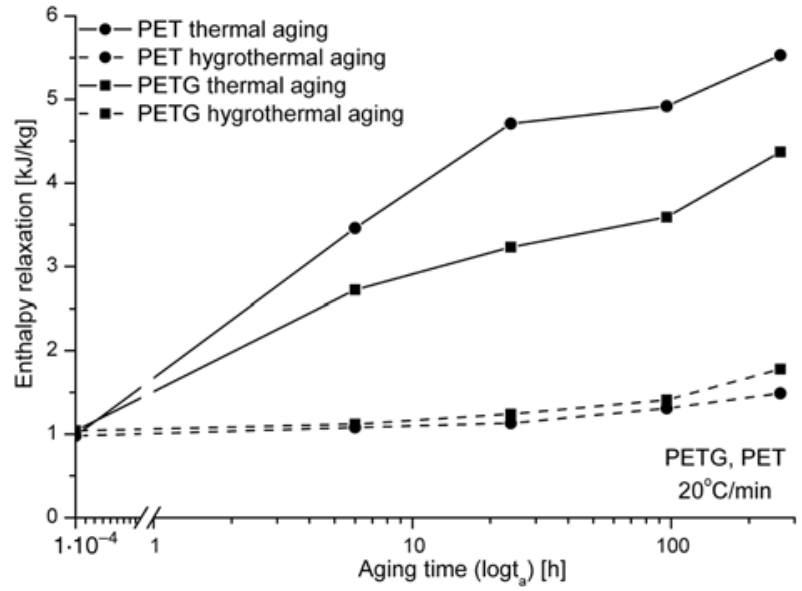

Figure 4. Change of enthalpy relaxation $(\Delta H)$ as a function of aging time $\left(\log t_{a}\right)$

value (RJ) since it is not in plasticized state. It can be stated that the physical aging of the polymer becomes much slower by hygrothermal aging owing to the presence of water, which can be assessed by the change of the enthalpy relaxation. The enthalpy relaxation is smaller 4.5 times for PETG and 9 times for PET than measured after thermal aging.

\subsection{EWF tests}

Figure $5 \mathrm{a}$ and $5 \mathrm{~b}$ show tensile curves of DEN-T specimens cut from thermally aged PETG and from hygrothermally aged PET sheets. By thermal aging, the maximum force increases and the tearing related deformation decreases as a function of aging time. By hygrothermal aging, the maximal load decreases up to 6 hours and the deformation increases giving evidence to the plasticizing effect of diffused water. Comparing the tensile curve of DEN-T aged for 264 hours to that aged for 6 hours, one can notice that the maximum force increases and the tearing related deformation decreases. This refers to physical aging.
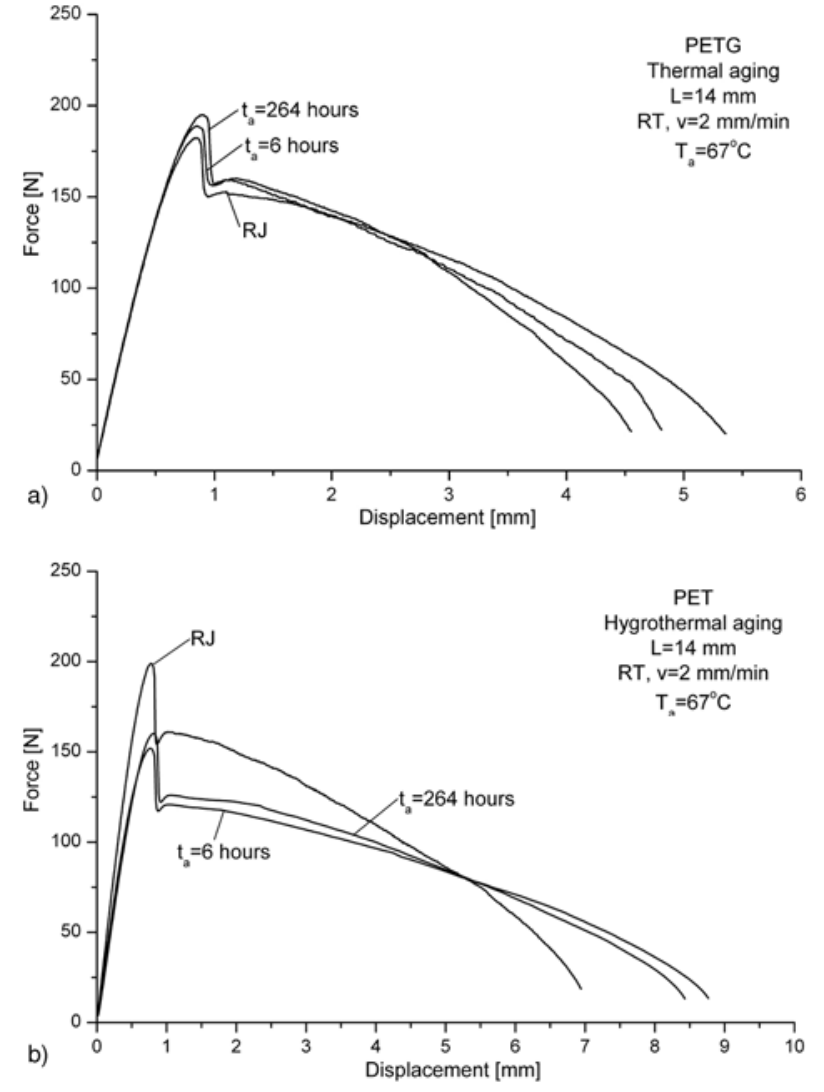

Figure 5. a) Force-deformation curves of DDEN-T specimens $(L=14 \mathrm{~mm})$ of PETG in RJ stage and thermally aged for 6 and 264 hours, b) Forcedeformation curves of DDEN-T specimens $(L=14 \mathrm{~mm})$ of PET in RJ stage and hygrothermally aged for 6 and 264 hours

Table 2 and 3 list the specific essential work $\left(w_{e}\right)$, specific ligament related essential work of fracture component $\left(w_{e, y}\right)$, specific plastic fracture work $\left(\beta w_{p}\right)$ and its necking+tearing related component $\left(\beta^{\prime \prime} w_{p, n}\right)$ for both investigated polyesters in case of thermal and hygrothermal aging, respectively. The tables also contain the correlation coefficients $(R)$. It can be seen that in case of the $w_{e}$ no aging-related changes can be detected, while $w_{e, y}$ increases with the increasing aging time for both materials and its tendency is similar to that of yield stress and

Table 2. EWF parameters $\left(w_{e}, w_{e, y}, \beta w_{p}, \beta^{\prime \prime} w_{p, n}\right)$ for PET and PETG sheets thermally/hygrothermally aged for $0 \ldots 264$ hours

\begin{tabular}{|c|c|c|c|c|c|c|c|c|c|c|c|c|}
\hline \multirow{3}{*}{$\begin{array}{c}\text { Aging } \\
\text { time } \\
{[\mathrm{h}]}\end{array}$} & \multicolumn{12}{|c|}{ Thermal aging } \\
\hline & \multicolumn{6}{|c|}{ PET } & \multicolumn{6}{|c|}{ PETG } \\
\hline & $\begin{array}{c}\mathrm{We}_{\mathrm{e}} \\
{\left[\mathrm{kJ} / \mathrm{m}^{2}\right]}\end{array}$ & $\begin{array}{c}\mathbf{w e}_{\mathrm{e}, \mathbf{y}} \\
{\left[\mathrm{kJ} / \mathbf{m}^{2}\right]}\end{array}$ & $\begin{array}{c}\beta \mathbf{w}_{\mathbf{p}} \\
{\left[\mathbf{M J} / \mathbf{m}^{3}\right]}\end{array}$ & $\begin{array}{c}\mathbf{R} \\
{[-]}\end{array}$ & $\begin{array}{c}\beta^{\prime \prime} \mathbf{w}_{\mathbf{p}, \mathbf{n}} \\
{\left[\mathbf{M J} / \mathbf{m}^{3}\right]}\end{array}$ & $\begin{array}{c}\mathbf{R} \\
{[-]}\end{array}$ & $\begin{array}{c}\mathrm{we}_{\mathrm{e}} \\
{\left[\mathrm{kJ} / \mathrm{m}^{2}\right]}\end{array}$ & $\begin{array}{c}\mathbf{w e}_{\mathrm{e}, \mathbf{y}} \\
{\left[\mathbf{k J} / \mathbf{m}^{2}\right]}\end{array}$ & $\begin{array}{c}\boldsymbol{\beta} \mathbf{w}_{\mathbf{p}} \\
{\left[\mathbf{M J} / \mathbf{m}^{3}\right]}\end{array}$ & $\begin{array}{c}\mathbf{R} \\
{[-]}\end{array}$ & $\begin{array}{c}\beta^{\prime \prime} \mathbf{w}_{\mathbf{p}, \mathbf{n}} \\
{\left[\mathrm{MJ} / \mathbf{m}^{3}\right]}\end{array}$ & $\begin{array}{c}\mathbf{R} \\
{[-]}\end{array}$ \\
\hline $0(\mathrm{RJ})$ & 50.0 & 13.6 & 10.4 & 0.99 & 9.0 & 0.99 & 39.1 & 12.4 & 7.6 & 0.99 & 6.4 & 0.99 \\
\hline 6 & 51.7 & 14.3 & 10.3 & 0.99 & 8.6 & 0.99 & 40.8 & 12.9 & 7.3 & 0.99 & 5.8 & 0.98 \\
\hline 24 & 53.7 & 14.4 & 9.7 & 0.99 & 7.6 & 0.99 & 42.7 & 13.7 & 6.9 & 0.98 & 5.4 & 0.97 \\
\hline 96 & 53.4 & 15.3 & 9.8 & 0.99 & 7.9 & 0.99 & 40.6 & 14.4 & 6.7 & 0.99 & 5.1 & 0.99 \\
\hline 264 & 48.9 & 15.7 & 9.8 & 0.99 & 8.1 & 0.98 & 43.1 & 15.4 & 6.4 & 0.99 & 4.7 & 0.98 \\
\hline
\end{tabular}


Table 3. EWF parameters $\left(w_{e}, w_{e, y}, \beta w_{p}, \beta^{\prime \prime} w_{p, n}\right)$ for PET and PETG sheets thermally/hygrothermally aged for $0 \ldots 264$ hours

\begin{tabular}{|c|c|c|c|c|c|c|c|c|c|c|c|c|}
\hline \multirow{3}{*}{$\begin{array}{c}\text { Aging } \\
\text { time } \\
{[\mathrm{h}]}\end{array}$} & \multicolumn{12}{|c|}{ Hygrothermal aging } \\
\hline & \multicolumn{6}{|c|}{ PET } & \multicolumn{6}{|c|}{ PETG } \\
\hline & $\begin{array}{c}\mathbf{W e}_{\mathrm{e}} \\
{\left[\mathrm{kJ} / \mathrm{m}^{2}\right]}\end{array}$ & $\begin{array}{c}w_{e, y} \\
{\left[\mathrm{~kJ} / \mathbf{m}^{2}\right]}\end{array}$ & $\begin{array}{c}\beta \mathbf{w}_{\mathbf{p}} \\
{\left[\mathbf{M J} / \mathbf{m}^{3}\right]}\end{array}$ & $\begin{array}{c}\mathbf{R} \\
{[-]}\end{array}$ & $\begin{array}{c}\beta^{\prime \prime} \mathbf{w}_{\mathbf{p}, \mathbf{n}} \\
{\left[\mathrm{MJ} / \mathbf{m}^{3}\right]}\end{array}$ & $\begin{array}{c}\mathbf{R} \\
{[-]}\end{array}$ & $\begin{array}{c}w_{\mathbf{e}} \\
{\left[\mathrm{kJ} / \mathrm{m}^{2}\right]}\end{array}$ & $\begin{array}{c}\mathbf{W}_{\mathrm{e}, \mathrm{y}} \\
{\left[\mathrm{kJ} / \mathrm{m}^{2}\right]}\end{array}$ & \begin{tabular}{c|}
$\boldsymbol{\beta} \mathbf{w}_{\mathbf{p}}$ \\
{$\left[\mathbf{M J} / \mathbf{m}^{3}\right]$}
\end{tabular} & $\begin{array}{c}\mathbf{R} \\
{[-]}\end{array}$ & $\begin{array}{c}\beta^{\prime \prime} \mathbf{w}_{\mathbf{p}, \mathbf{n}} \\
{\left[\mathrm{MJ} / \mathbf{m}^{3}\right]}\end{array}$ & $\begin{array}{c}\mathbf{R} \\
{[-]}\end{array}$ \\
\hline $0(\mathrm{RJ})$ & 50.0 & 13.6 & 10.4 & 0.99 & 9.0 & 0.99 & 39.1 & 12.4 & 7.6 & 0.99 & 6.4 & 0.99 \\
\hline 6 & 40.4 & 7.2 & 10.5 & 0.99 & 9.4 & 0.99 & 39.0 & 8.1 & 7.1 & 0.99 & 5.8 & 0.98 \\
\hline 24 & 40.0 & 6.4 & 10.5 & 0.99 & 9.3 & 0.99 & 29.1 & 8.8 & 7.8 & 0.99 & 6.5 & 0.99 \\
\hline 96 & 43.5 & 5.5 & 10.2 & 0.99 & 8.9 & 0.99 & 31.9 & 8.9 & 7.8 & 0.99 & 6.5 & 0.99 \\
\hline 264 & 42.9 & 8.4 & 10.1 & 0.99 & 9.0 & 0.99 & 33.5 & 10.7 & 7.4 & 0.99 & 6.2 & 0.99 \\
\hline
\end{tabular}

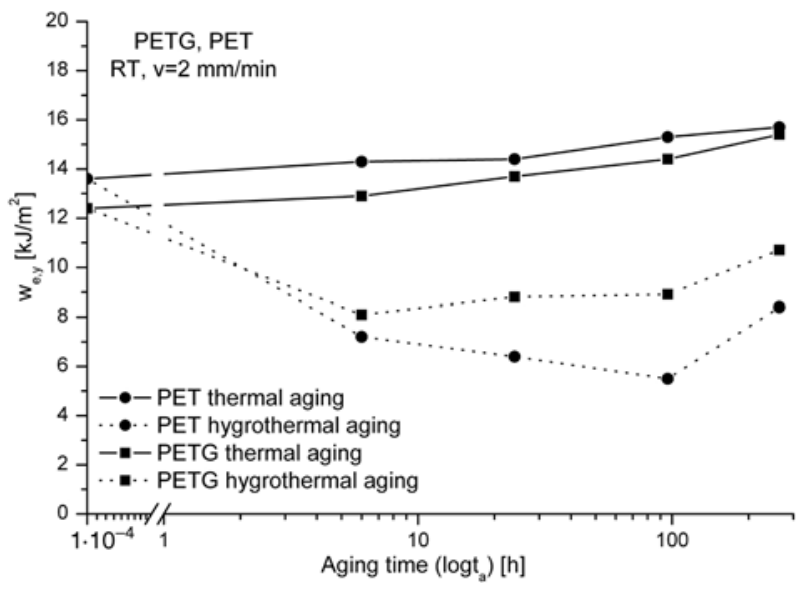

Figure 6. Change of the specific yielding-related essential work of fracture $\left(\mathrm{w}_{e, y}\right)$ as a function of aging time $\left(\log t_{a}\right)$

enthalpy relaxation (Figure 6). By hygrothermally aged samples $w_{e, y}$ shows a similar trend to yield stress: in the first 6 hours of aging the materials reach their saturation state $\left(\sigma_{y}\right.$ and $w_{e, y}$ decrease), after 6 hours physical aging takes place $\left(\sigma_{y}\right.$ and $w_{e, y}$ increase slightly, cf. Figures 2 and 6). Based on the result one can state that the specific yielding related work of fracture $\left(w_{e, y}\right)$ is a suitable parameter for assessing the thermal and hygrothermal aging of polyesters.

In case of thermal aging $\beta w_{p}$, which represents the resistance of the material against crack propagation - as expected -, decreases with physical aging. For PETG it decreases monotonously but for PET no further decrease can be experienced after 24 hours. The reason is that little crystallization may have taken place in the crystallizable amorphous PET subjected to further aging. For the specific necking+tearing related plastic work of fracture $\left(\beta^{\prime \prime} w_{p, n}\right)$ the above mentioned tendency appears more significantly since in this segment crack propagation occurs and a completely plastic zone is formed (Figure 7). During hygrothermal aging the plasticizer effect [17] of the diffused water increases the

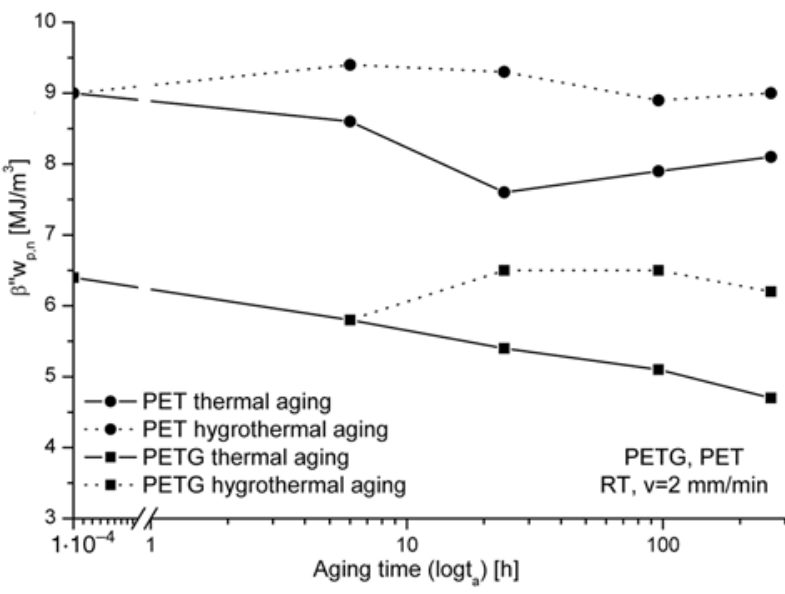

Figure 7. Change of the specific necking+tearing-related plastic work of fracture $\left(\beta^{\prime \prime} w_{p, n}\right)$ as a function of aging time $\left(\log t_{a}\right)$

plastic fracture work $\left(\beta w_{p}\right)$, while physical aging has an opposite effect. The question is which effect dominates, or whether these two effects cancel each other. In the present case $\beta w_{p}$ shows no significant change as a function of aging time (Figure 7), which allow us to opt for the latter possibility. Investigating $\beta^{\prime \prime} w_{p, n}$ a similar conclusion can be drawn as for $\beta w_{p}$. Hence $\beta w_{p}$ and $\beta^{\prime \prime} w_{p, n}$ can represent the effect of either physical aging or plasticizer, but if both conditions are present together this statement is not true.

\section{Discussion}

The effect of physical aging is different for polyesters in the presence of various plasticizers. Adding plasticizer (NPGDB [1]) its effect is more significant, since the glass temperature decreases considerably. Absorbed water reduces $T_{g}$, because of the presence of humidity a part of the polymer/ polymer interaction changes due to polymer/water interactions. For immersed samples the distilled water ensures the equilibrium water content in the polymer. When the polymer relaxes after immers- 
ing in water and the amount of polymer/polymer interaction increases, water will be present in equilibrium amount (corresponding to the ambient conditions) and ensures the permanence of plastic deformation. Accordingly, the enthalpy relaxation changes less than in case of thermal degradation (Figure 4). The plasticizer effect of water has practical importance since less physical aging takes place, so life cycle of PET bottles can be extended. Physical aging increases yield stress and the plasticizing effect of water decreases it. In Figure 2 one can see that a little physical aging superposes on the plasticizer effect of the water in case of hygrothermal aging (Figure 4).

The specific essential work $\left(w_{e}\right)$ does not change due to aging. Specific yielding related essential work of fracture component $\left(w_{e, y}\right)$ shows also a good correlation with yield stress and enthalpy relaxation. The specific plastic work and its $\beta^{\prime \prime} w_{p, n}$ component decreases in case of thermal aging, and above ca. $1 \mathrm{wt} \%$ water content they are independent of physical aging.

Based on the results one can state that the specific yielding related essential work of fracture component $\left(w_{e, y}\right)$ measured on specimens loaded under plane stress condition is suitable for assessing physical aging independently of humidity content. A good linear correlation can be found between $w_{e, y}$ and $\sigma_{y}$ (Figure 8).

In the case of enthalpy relaxation a linear regression line cannot be fitted to each point determined on the thermally and hygrothermally aged specimens, since the diffused water does not influence the value of $\Delta H$ but it does $w_{e, y}$. Therefore only those values can be correlated which are measured on the thermally aged samples (Figure 9).

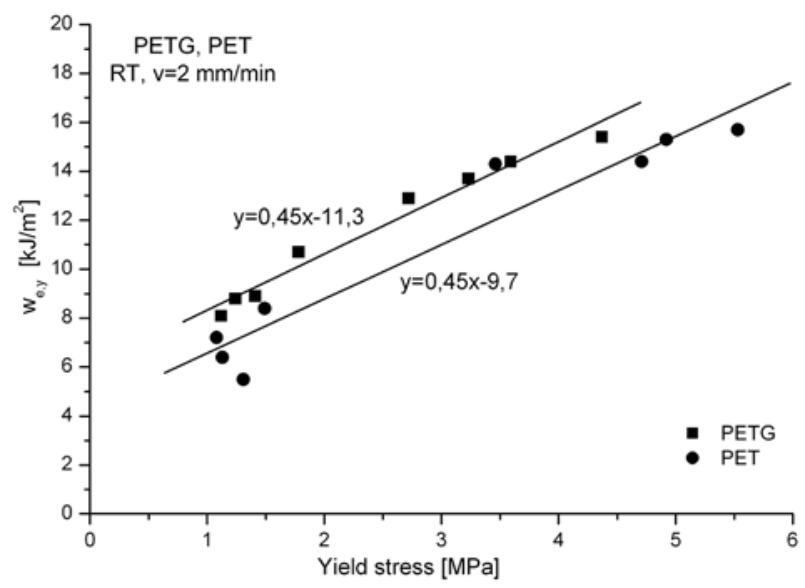

Figure 8. Correlation between $w_{e, y}$ and $\sigma_{y}$

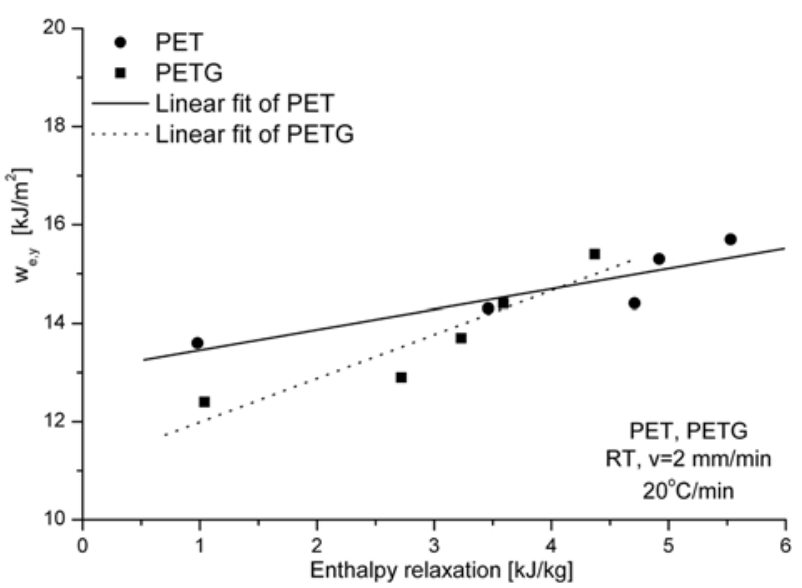

Figure 9. Correlation between $w_{e, y}$ and $\Delta H$

\section{Conclusions}

Based on this work devoted to assessing the inplane (plane stress) fracture toughness of physically aged polyester sheets after thermal and hygrothermal aging using the essential work of fracture (EWF) method, the following conclusions can be drawn:

- The effect of physical aging caused by thermal and hygrothermal aging under glass temperature $\left(T_{g}\right)$ can be followed by measuring the change of yield stress $\left(\sigma_{y}\right)$ and the specific yielding-related essential work of fracture $\left(w_{e, y}\right)$.

- The specific necking+tearing related plastic work of fracture component $\left(\beta^{\prime \prime} w_{p, n}\right)$ can also be a suitable factor for assessing physical aging. This parameter decreases with the aging time. With the embrittlement of the polyesters, associated with the increasing yield stress, the resistance to crack propagation decreases.

\section{Acknowledgements}

This study was supported by Hungarian Scientific Research Fund (OTKA NI62729).

\section{References}

[1] Karger-Kocsis J., Bárány T., Moskala E. J.: Plane stress fracture toughness of physically aged plasticized PETG as assessed by the essential work of fracture (EWF) method. Polymer, 44, 5691-5699 (2003).

[2] Bárány T., Ronkay F., Karger-Kocsis J., Czigány T.: In-plane and out-of-plane fracture toughness of physically aged polyesters as assessed by the essential work of fracture (EWF) method. International Journal of Fracture, 135, 251-265 (2005).

[3] Bárány T., Karger-Kocsis J., Czigány T.: Effect of hygrothermal aging on the essential work of fracture 
response of amorphous poly(ethylene terephthalate) sheets. Polymer Degradation and Stability, 82, 271278 (2003).

[4] Karger-Kocsis J., Moskala E. J.: Toughness response of amorphous (co)polyesters using the essential work of fracture approach, SPE-ANTEC, 60, 2002, Vol. II., 1751-1755.

[5] Lu X., Hay J. N.: The effect of physical aging on the rates of cold crystallization of poly(ethylene terephthalate). Polymer, 41, 7427-7436 (2000).

[6] Aref-Azar A., Arnoux F., Biddlestone F., Hay J. N.: Physical aging in amorphous and crystalline polymers. Part 2. Polyethylene terephthalate. Thermochimica Acta, 273, 217-229 (1996).

[7] Liu C-H., Nairn J. A.: Using the essential work of fracture method for studying physical aging in thin, ductile, polymeric films. Polymer Engineering and Science, 38, 186-193 (1998).

[8] Karger-Kocsis J.: Fracture and fatigue behavior of amorphous (co)polyesters as a function of molecular and network variables. in 'Handbook of Thermoplastic Polyesters' (ed.: Fakirov S.) Wiley-VCH, Weinheim, 717-753 (2002).

[9] Hashemi S.: Temperature and deformation rate dependence of the work of fracture in polycarbonate (PC) film. Journal of Materials Science, 35, 58515856 (2000).

[10] Ching E. C. Y., Li R. K. Y., Mai Y-W.: Effects of gauge length and strain rate on fracture toughness of polyethylene terephthalate glycol (PETG) film using the essential work of fracture (EWF) analysis. Polymer Engineering and Science, 40, 310-319 (2000).

[11] Arkhireyeva A., Hashemi S.: Effect of temperature on work of fracture parameters in poly(ether-ether ketone) (PEEK) film. Engineering Fracture Mechanics, 71, 789-804 (2004).

[12] Arkhireyeva A., Hashemi S.: Influence of temperature on plane stress ductile fracture of poly(ethylene terephthalate) film. Plastics, Rubber and Composites, 30, 125-131 (2001).

[13] Arkhireyeva A., Hashemi S.: Fracture behaviour of polyethylene naphthalate (PEN). Polymer, 43, 289300 (2002).

[14] Karger-Kocsis J., Czigány T., Moskala E. J.: Deformation rate dependence of the essential and nonessential work of fracture parameters in an amorphous copolyester. Polymer, 39, 3939-3944 (1998).

[15] Arkhireyeva A., Hashemi S.: Effect of temperature on fracture properties of an amorphous poly(ethylene terephthalate) (PET) film. Journal of Materials Science, 37, 3675-3683 (2002).

[16] Ferrer Balas D., Maspoch M. L1., Martinez A. B., Santana O. O.: On the essential work of fracture method: Energy partitioning of the fracture process in iPP films. Polymer Bulletin, 42, 101-108 (1999).

[17] Chen Y., Lin Z., Yang S.: Plasticization and crystallization of poly(ethylene terephthalate) induced by water. Journal of Thermal Analysis, 52, 565-568 (1998). 